\title{
Bilateral Palatin Tonsil Yerleşimli Epidermoid Kistler: Bir Olgu Sunumu
}

\section{Epidermoid Cysts Localized in Bilateral Palatine Tonsils: A Case Report Gözde Çakırsoy Çakar, Mustafa Kösem, Fahri Yılmaz}

Sakarya Üniversitesi Eğitim ve Araştırma Hastanesi, Sakarya/Türkiye

\section{Yazışma Adresi / Correspondence:} Gözde Çakırsoy Çakar

Sakarya Eğitim Araştırma Hastanesi Merkez Kampüsü/Sakarya

T: +90 $5342950413 \quad$ E-mail: gozdec123@gmail.com

Geliş Tarihi / Received : 04.10.2018 Kabul Tarihi / Accepted : 12.12.2018

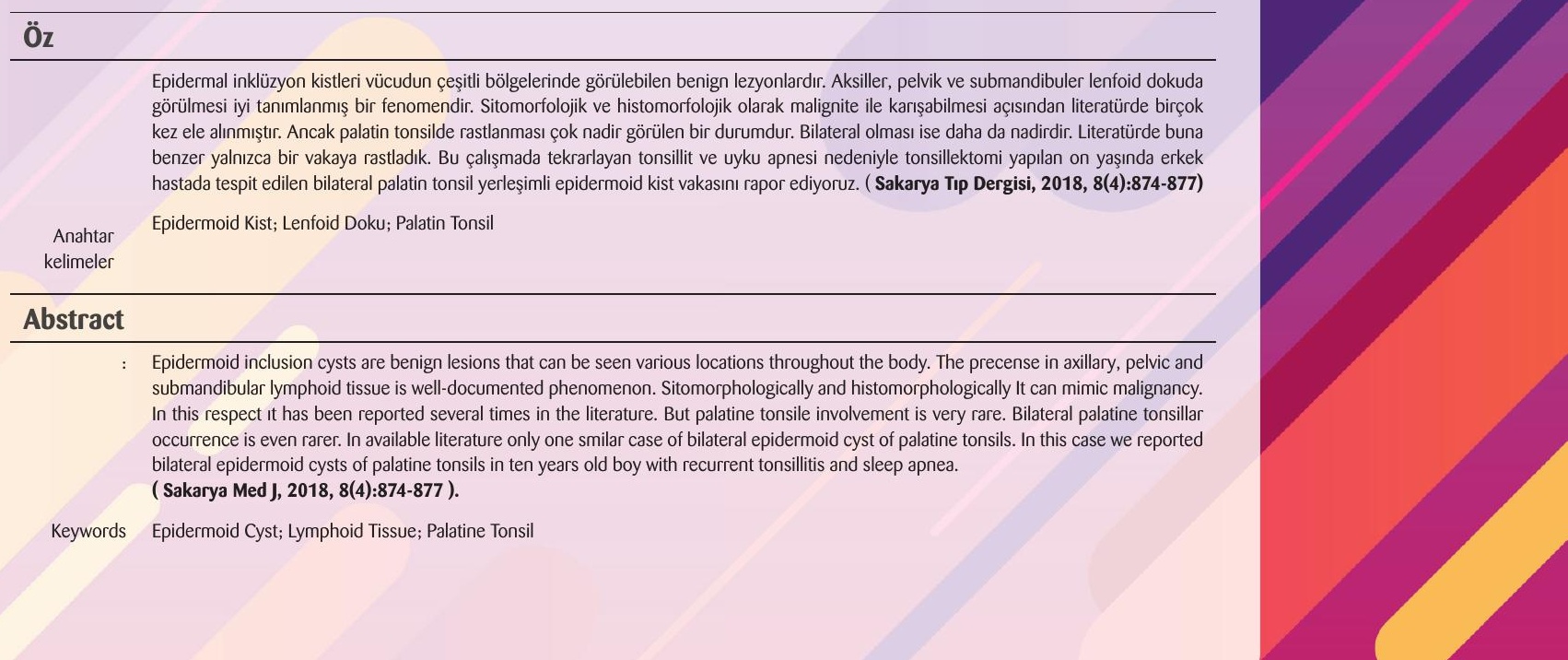


Sakarya TIp Dergisi 2018;8(4):874-877

ÇAKAR ve Ark. Bidermoid Kistler: Bir Olgu Sunumu

\section{Giriş}

Epidermoid kistler, ektodermal dokudan köken alan, fetal dönemde oluşan ya da travmaya bağı implante olan epitelden gelişen benign lezyonlardır. ${ }^{1}$ Aksiller, pelvik ve submandibuler lenf nodlarında görülmesi iyi tanımlanmış bir fenomendir. ${ }^{2}$ Servikal lenf nodlarında da nadiren görülebilir. ${ }^{3}$ Vücudun çeşitli bölgelerinde görülebilmekle birlikte $\% 1.6$ 'sı oral kavitede izlenir. ${ }^{4}$ Oral kavitede en sık yerleşim yerleri sublingual, submental, submandibular, labial/lingual ve bukkal mukozadır. Tonsillerde görülmesi ise oldukça nadirdir. ${ }^{5}$ Palatin tonsillerde bilateral görülmesi ise daha da nadirdir. İngilizce literatürde buna benzer yayınlanmış tek olgu vardır. ${ }^{6}$ Bizim vakamı tekrarlayan tonsillit ve uyku apnesi nedeniyle tonsilektomi yapılan on yaşında erkek hastadır. Tonsillerin patolojik incelemesinde rastlantısal olarak bilateral epidermoid kistler tespit edilmiştir. Vakamız, nadir görülen bir olgu olması yanında lenfoid dokuda, histomorfolojik ve sitomorfolojik olarak skuamöz hücreli karsinom ayırıcı tanısında akılda tutulması gereken bir antite olması nedeniyle burada tartışıımışıı. ${ }^{7,8}$

\section{Olgu Sunumu:}

Tekrarlayan tonsillit ve uyku apnesi nedeniyle kiniğe başvuran on yaşında erkek hastanın muayenesinde palatin tonsillerde hafif büyüme dışında bulgu saptanmadı. Servikal lenf nodlarında büyüme ve hassasiyet yoktu. Rutin laboratuvar tahlilleri normal sınırlar içindeydi. Genel anestezi ile yapılan operasyonda alınan tonsillerin makroskopik incelemesinde tonsillerin boyutları $1,5 \times 1 \times 0,8 \mathrm{~cm}$ ve $1,7 \times 1 \times 1 \mathrm{~cm}$ idi. Tonsillerde makroskopik olarak belirgin hipertrofik görünüm veya asimetrik büyüme saptanmadı. Herbirinin kesi yüzünde $0,6 \mathrm{~cm}$ ve $0,4 \mathrm{~cm}$ çaplarında kirli sarı renkli keratinöz materyal içeren birer adet kistik yapı izlendi. Histomorfolojik incelemede kronik tonsillit bulguları yanısıra, çok katlı yassı epitel ile döşeli, içerisinde lameller keratinöz materyal bulunan kistler izlendi.(Resim 1,2) Vaka, bilateral intratonsiller epidermoid kist olarak rapor edildi.

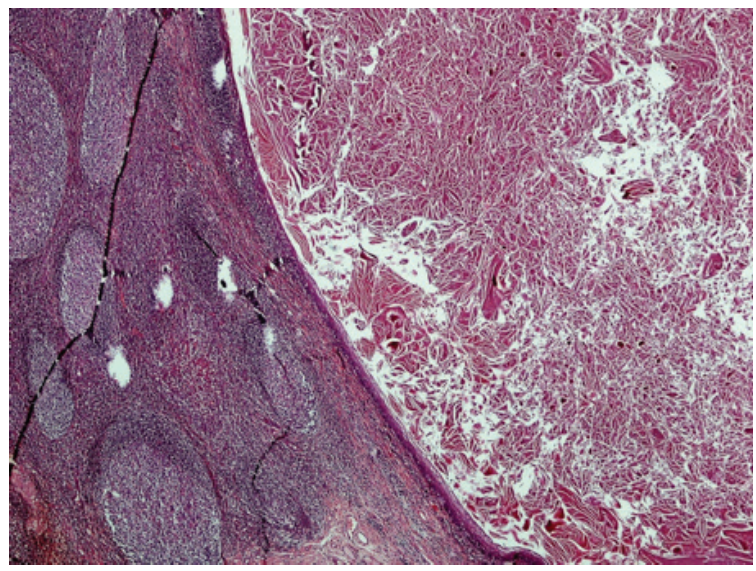

Resim 1 ve 2. Tonsilin içinde, benign skuamöz epitel ile döşeli, keratin debris içeren kistler

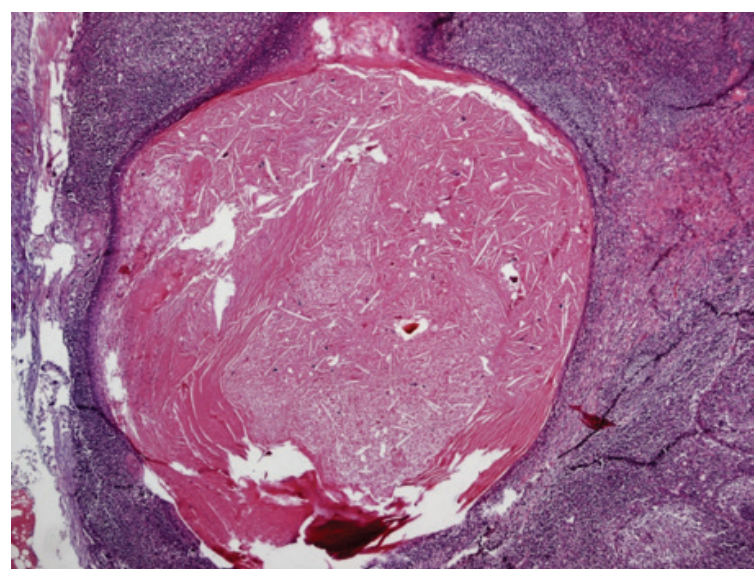
(H\&E, x40, H\&E x100). 


\section{Tartışma}

Epidermoid kistler, vücudun birçok bölgesinde izlenebilen ektodermden köken alan, doğuştan ya da travmaya bağı, epitelin ekilmesi sonucu oluşan benign lezyonlardır. ${ }^{1}$ Epidermoid kistlerin \%1.6'sı oral kavitede görülmekle birlikte tonsillerde görülme olasılığı oldukça nadirdir. ${ }^{1,5}$ Vakamız literatürdeki ikinci bilateral intratonsiller epidermal kist olması nedeniyle dikkat çekicidir. Epidermoid kistlerin heterotopik olarak pelvik, aksiller ve servikal lenf nodlarında görülmesi literatürde iyi tanımlanmış bir fenomendir. ${ }^{2,3}$ Palatin tonsillerde görülmesi ise tonsillerin histolojik yapısında yüzeyde çok katlı yassı epitelin olması nedeniyle heterotopik bir yerleşim değildir. Tonsillerin histolojik olarak çok katlı yassı epitele sahip olması, etiyolojide fetal dönemde anormal epitelyal komponent oluşumundan ziyade travma veya kronik inflamasyona sekonder geliştiğini düşündürmektedir. Ayrıca lenfoid dokuda görülebilen epidermoid kistlerin, özellikle çok sayıda olduğunda, sitomorfolojik ve histomorfolojik olarak skuamöz hücreli karsinom metastazı ile karışabileceği akılda tutulmalıdir. ${ }^{7,8}$

Sonuç olarak; tonsillit ön tanısıyla kliniğe başvuran ve bu nedenle opere edilen olgularda bizim olgumuzda olduğu gibi tonsillit dışında başka patolojilerin de olabileceği göz önünde bulundurulmalıdır. Bu amaçla tonsillit nedeniyle opere olan ve bilateral intratonsiller epidermal kist tanısı alan olgu nadir görülmesi nedeniyle sunulmuştur. 
Keles E, Kaplama ME, Dolen T, Cobanoglu B. Epidermoid cyst localized in the palatine tonsil. J Oral Maxillofac Pathol. 2013; 17(1): 148.

2. Fellegra G, Carcangiu ML, Rosai J. Benign epithelial inclusions in axillary lymph nodes: Report of 18 cases and review of the literature. Am J Surg Pathol 2011; 35: 1123-1133.

3. Bahadur S, Pujani M, Jetley S. Epithelial inclusion cyst in a cervical lymph node: Report of a rare entity at an uncommon location. Ann Med Health Sci Res. 2016; 6(2): 137-138.

4. Rajayogesvaran V, Eveson JW. Epidermoid cyst of the buccal mucosa. Oral Surg Oral Med Oral Pathol. 1989; 67:181-184.

5. Sandhya PG, Lavanya M, Varun K, Arun Kumar SP. Epidermoid cyst of the tonsil: an incidental finding. İnternational Journal of Advances in Case reports. 2015; 2(12): 777-779.
6. Mohsenifar Z, Mahdavi N, Bagheri S. Bilateral multiple lymphoepithelial cysts of palatine tonsils. Iranian Journal of Pathol. 2013; 8(1): 48-54

7. Nikumbh DB, Nikumbh RD, More H. İntratonsillar multiple epidermal inclusion cysts-A tumor mimic. Archives of cytology and histopathology research. 2017; 2(1):18-20.

8. Fruehwald-Pallamar J, Li CQ, Hasteh F,Hauff S, Davidson TM, Mafee MM Nodal inclusion cyst in a cervical lymph node. Neurographics. 2012; 2: $163-166$ 